\title{
Fabrication and Characterisation of Nanoscale Ni-CGO Electrode from Nano- composite Powders
}

\author{
Jingyi Chen ${ }^{\mathrm{a}, \mathrm{d}}$, Mengzheng Ouyang ${ }^{\mathrm{b}}$, Paul Boldrin ${ }^{\mathrm{b}}$, Xinhua Liu ${ }^{\mathrm{a}}$, Jawwad A. Darr ${ }^{\mathrm{c}}$, Alan \\ Atkinson $^{\mathrm{d}}$ and Nigel Brandon ${ }^{\mathrm{b}}$ \\ ${ }^{a}$ Dyson School of Design, Imperial College London, London SW7 2AZ, UK \\ ${ }^{\mathrm{b}}$ Department of Earth Science and Engineering, Imperial College London, London SW7 \\ 2AZ, UK \\ ${ }^{c}$ Department of Chemistry, University College London, London WC1H 0AJ, UK \\ ${ }^{\mathrm{d}}$ Department of Materials, Imperial College London, SW7 2AZ, UK
}

Incorporating nanoparticles into SOC electrode is a viable method to improve the electrochemical performance. In this work, nanoparticles of $\mathrm{NiO}$ and gadolinia-doped ceria (CGO) approximately $10 \mathrm{~nm}$ in diameter fabricated using a continuous hydrothermal flow synthesis are made into nano-structured SOC fuel electrodes via mixing and co-sintering. Both the Ni and CGO are of 50-100 $\mathrm{nm}$ in diameter in the final electrode. FIB-SEM 3-D tomography is carried out on the nanoscale Ni-CGO electrode which has been aged for $70 \mathrm{~h}$, showing a high active triple phase boundary density of $3 \mu \mathrm{m}^{-2}$ and a high active double phase boundary density of $2 \mu \mathrm{m}^{-1}$. The total polarisation resistance of the electrode is stable at $0.20 \Omega \mathrm{cm}^{2}$ under open circuit conditions at $800{ }^{\circ} \mathrm{C}$ annealing in humidified $5 \% \mathrm{H}_{2}-\mathrm{N}_{2}$.

\section{Introduction}

Nanoscale electrode design has been a promising approach to enhance the electrochemical performance of solid oxide cell (SOC) electrode. Nanoparticles have a high surface to volume ratio, which leads to an increase in reaction site per unit volume. Very recently, Lee et al. showed that infiltrated lanthanum doped strontium titanate (LST) with nanoparticles of $\mathrm{Ni}$ and gadolinia-doped ceria (CGO) remarkably reduced the electrodes' polarization resistance from $68.5 \Omega \mathrm{cm}^{2}$ to $0.12 \Omega \mathrm{cm}^{2}$ at $700{ }^{\circ} \mathrm{C}$ in $3 \% \mathrm{H}_{2} \mathrm{O}$ $\mathrm{H}_{2}$ (1). The polarization resistance was also observed to be influenced by the mass loading and dispersion state of the nanoparticles. Nanoparticles can also serve as catalyst to enhance sulphur poisoning tolerance and coking resistance in the fuel electrode. For example, exsolved Co-Fe nanoparticles on LSCrFeCo10 perovskite showed steady power density in $20 \mathrm{ml} \mathrm{min}^{-1} \mathrm{C}_{3} \mathrm{H}_{8}-3 \% \mathrm{H}_{2} \mathrm{O}$ and scanning electron microscopy (SEM) images showed very few carbon fibre and filament formation (2).

Fuel cell electrodes are porous materials, where the electrochemical reactions take place at either the double phase boundary (DPB) for mixed-ionic-and-electronicconductor (MIEC) and triple phase boundary (TPB) for composite of ionic and electronic conductors. Integrating nanoparticles change both the DPB and TPB densities, as well as the network structural properties (porosity, tortuosity etc.) of SOC electrodes. Simulations have proved that reducing the particle size of the nickel and ceramic phases leads to an increase in TPB densities. A geometrical model adopted by Janardhanan et al. 
(3) for porous composite electrodes predicted that with $50 \%$ porosity, the TPB density increases from 1 to $15 \mu^{-2}$ when the particle size of the mono-dispersed particles reduces from 5 to $1 \mu \mathrm{m}$. Infiltrating $\mathrm{Ni}$ nanoparticles in the anode active layers in the commercial Ni-YSZ SOFC increases the TPB density from $2.4 \mu \mathrm{m}^{-2}$ to $8.4 \mu \mathrm{m}^{-2}$ as demonstrated in the work of $\mathrm{Lu}$ and co-workers' (4).

Many different synthesis methods have been used in making nanostructured electrodes for SOC, including sol-gel method, hydrothermal method, impregnation, physical vapour deposition and sputtering (5). Impregnation of salt solution is one of the popular approaches due to its versatility to incorporate a wide range of materials, especially those low-melting point phases susceptible to high temperature sintering (6). However, to achieve a sufficient mass loading, infiltration process typically needs to be repeated for more than 10 cycles $(7,8)$. Therefore in this work, we explored fabrication of nanostructured electrode using hydrothermally synthesised composite nanoparticles in continuous water flows as described in (9) and tape casting. Nanostructured Ni-CGO electrodes were fabricated by co-sintering and their microstructures characterised by 2-D SEM images and 3-D focused ion beam (FIB)-SEM tomography. The electrochemical performance is quantified by the area specific resistance (ASR) measured by electrochemical impedance microscopy (EIS).

\section{Experimental}

During the hydrothermal synthesis, aqueous salt of $\mathrm{Ni}$ nitrate, cerium ammonium nitrate and nitrates with hydrogen peroxide were fed to a continuous hydrothermal reactor. Rapid hydrolysis and co-precipitation took place in the streams of superheated water at $450{ }^{\circ} \mathrm{C}$ and $22.1 \mathrm{MPa}$ in the jet mixer, where the $\mathrm{Ni}$ and CGO nanoparticles are thoroughly mixed. The particles were then cooled, collected as an aqueous slurry and recovered and washed to remove anions by centrifugation. The final slurry was ovendried at $70{ }^{\circ} \mathrm{C}$ to obtain the composite nanopowder.

The surface properties of the as-dried powder were quantified from its nitrogen adsorption and desorption isotherms. The as-dried powder was then calcined and milled for $24 \mathrm{~h}$ at $300 \mathrm{rpm}$ to break down the agglomerates formed during heat treatment. After that, the composite nanopowder was mixed with terpineol (Aldrich) solvent, binder (Hercules EC-N7) and dispersant (Hypermer KD15) using a magnetic stirrer and a triple roll mill to form a homogeneous ink. The ink was tape cast onto $8 \mathrm{~mol} \%$ YSZ substrates (fuelcellmaterials YSZ-2.0, $20 \mathrm{~mm}$ in diameter and $0.28 \mathrm{~mm}$ in thickness). The cast was dried at $70{ }^{\circ} \mathrm{C}$ for a day and then sintered at $1250{ }^{\circ} \mathrm{C}$ for $2 \mathrm{~h}$ to form NiO-CGO film. The $\mathrm{NiO}$ was finally reduced to $\mathrm{Ni}$ in $5 \% \mathrm{H}_{2}-\mathrm{N}_{2}$ at $800{ }^{\circ} \mathrm{C}$ for $1 \mathrm{~h}$.

The EIS measurement was carried out in a two-electrode set-up at $800{ }^{\circ} \mathrm{C}$ in humidified $5 \% \mathrm{H}_{2}-\mathrm{N}_{2}$. The frequency ranged from $10 \mathrm{MHz}$ to $0.1 \mathrm{~Hz}$ with a sinusoidal voltage of $0.02 \mathrm{~V}$. Current collection was made via porous Ni paste and Pt wire pick-ups. SEM images were taken by LEO Gemini 1525 Field Emission Gun SEM using in-lens detector. FIB-SEM slice-and-view images were taken by Zeiss Auriga Cross Beam with back-scattered electron detector and a milling current of $120 \mathrm{pA}$ using a $\mathrm{Ga}^{+}$beam. The sequential image stacks were de-noised, aligned and segmented using Avizo. 


\section{Results and Discussion}

The NiO-CGO nanocomposite powder is characterised by SEM image as shown in Figure 1a and by the nitrogen adsorption and desorption isotherms in Figure 1b. The asdried powder in Figure 1a comprised of particles of $10 \mathrm{~nm}$ in diameter, which are loosely attached to each other. In Figure 1b, the isotherms show a slight hysteresis, which is caused by capillary condensation in very fine pores. The fine mesopores are between 2 and $50 \mathrm{~nm}$ in diameter. This matches with the morphology of the nanopowder shown in Figure 1a, where the space between the loosely bonded $10 \mathrm{~nm}$ particles become nanometre pore space which restricts gas access. From the isotherms in Figure $1 \mathrm{~b}$, the Brunauer-Emmett-Teller (BET) surface area is calculated to be $159 \mathrm{~m}^{2} \mathrm{~g}^{-1}$. Using the $\mathrm{t}-$ plot method, the surface area in the micropores is determined to be $53 \mathrm{~m}^{2} \mathrm{~g}^{-1}$ and the external area outside the pores $106 \mathrm{~m}^{2} \mathrm{~g}^{-1}$. The nanocomposite NiO-CGO powder has surface area one order of magnitude larger than the conventional SOFC anode powders, which are normally between $2-10 \mathrm{~m}^{2} \mathrm{~g}^{-1}$ and also larger than the BET surface area of 55 $\mathrm{m}^{2} \mathrm{~g}^{-1}$ reported by the templated mesoporous NiO-CGO powder in (10).

(a)

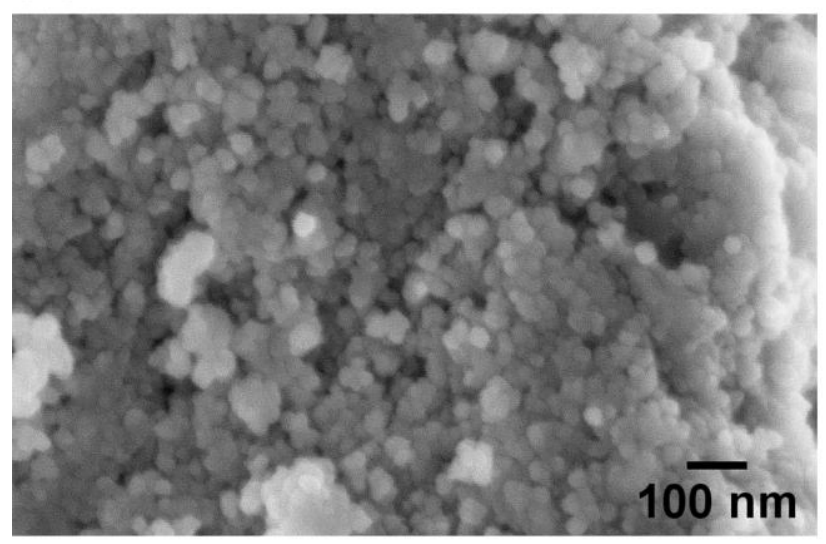

(b)

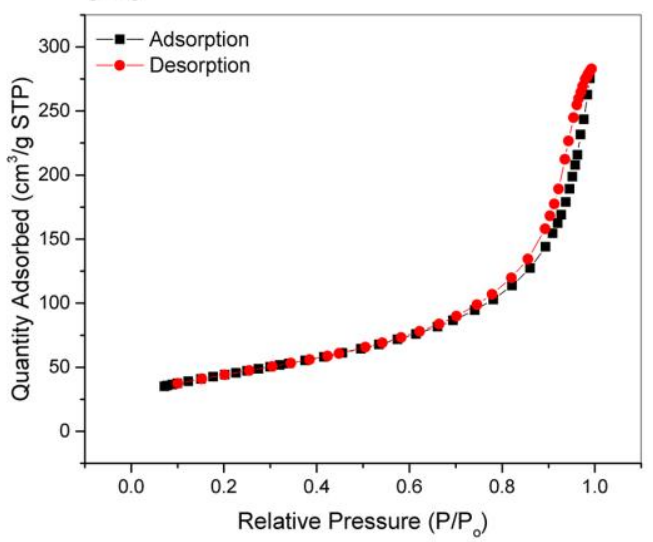

Figure 1 The SEM image of the as-dried nanocomposite NiO-CGO powder sprinkled on an adhesive carbon tape in (a) and the nitrogen adsorption/desorption isotherms of the asdried NiO-CGO powder measured at $77 \mathrm{~K}$.

The final Ni-CGO electrode after sintering and reduction is shown in Figure 2. The CGO particles are seen as percolated faceted grains of $100 \mathrm{~nm}$ in diameter. The $\mathrm{Ni}$ particles show very rough surfaces and appeared to be socketed in cavities. This is because the volume shrinkage when the $\mathrm{NiO}$ reduced to $\mathrm{Ni}$ creates extra pore space around them. Some Ni particles are $100 \mathrm{~nm}$ in diameters while the others are very fine, $10 \mathrm{~nm}$ in diameters as indicated by region highlighted in circles in Figure 2. There is an increase in the particle size during the electrode fabrication when the particles in Figure 2 are compared with those as-dried particles in Figure 1a, which is difficult to avoid especially during the sintering at $1300{ }^{\circ} \mathrm{C}$. Nevertheless, the particle diameter of $10-100$ $\mathrm{nm}$ is still one order of magnitude smaller than particles in a conventional tape-cast $\mathrm{Ni}$ CGO electrode, which are typically $1 \mu \mathrm{m}$. 


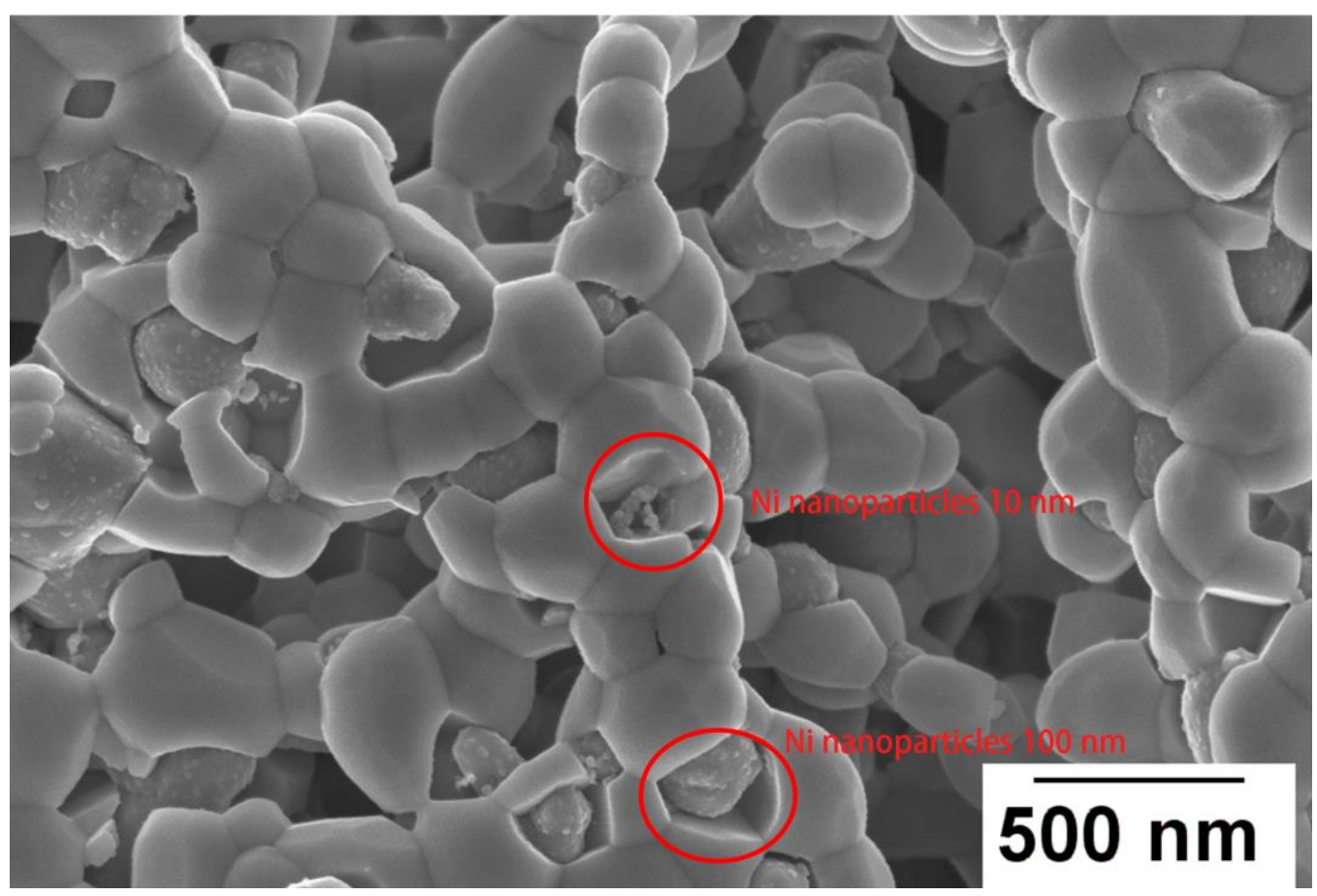

Figure 2 The SEM image of the top surface of the nanostructured Ni-CGO electrode on a YSZ substrate, after reduction at $800{ }^{\circ} \mathrm{C}$. The red circles point out a cluster of very fine Ni particles approximately $10 \mathrm{~nm}$ in size and another larger Ni particle $100 \mathrm{~nm}$ in size.

The electrochemical performance of the electrodes is measured by EIS. Amongst the four spectra shown in Figure 3, the one for the symmetrical cell aged for $20 \mathrm{~min}$ has the lowest total polarisation resistance of $0.17 \Omega \mathrm{cm}^{2}$. As the aging time increases, the total polarisation increases slightly till $0.20 \Omega \mathrm{cm}^{2}$. From Figure 3, the incremental increase with time is becoming smaller and smaller while the symmetrical cell is being annealed at $800{ }^{\circ} \mathrm{C}$. The increment in polarisation resistance between $10 \mathrm{~h}$ and $50 \mathrm{~h}$ is less than 0.01 $\Omega \mathrm{cm}^{2}$, indicating the electrodes are becoming stable in the time scale of $10-100 \mathrm{~h}$. The Nyquist plots in Figure 3 also indicate there are two physical processes (at least) with different characteristic frequencies, one at approximately $1 \mathrm{~Hz}$ and the other at approximately $100 \mathrm{~Hz}$. Our future work will look into deconvoluting the different responses in the impedance spectra and attribute them to their corresponding physical processes. 


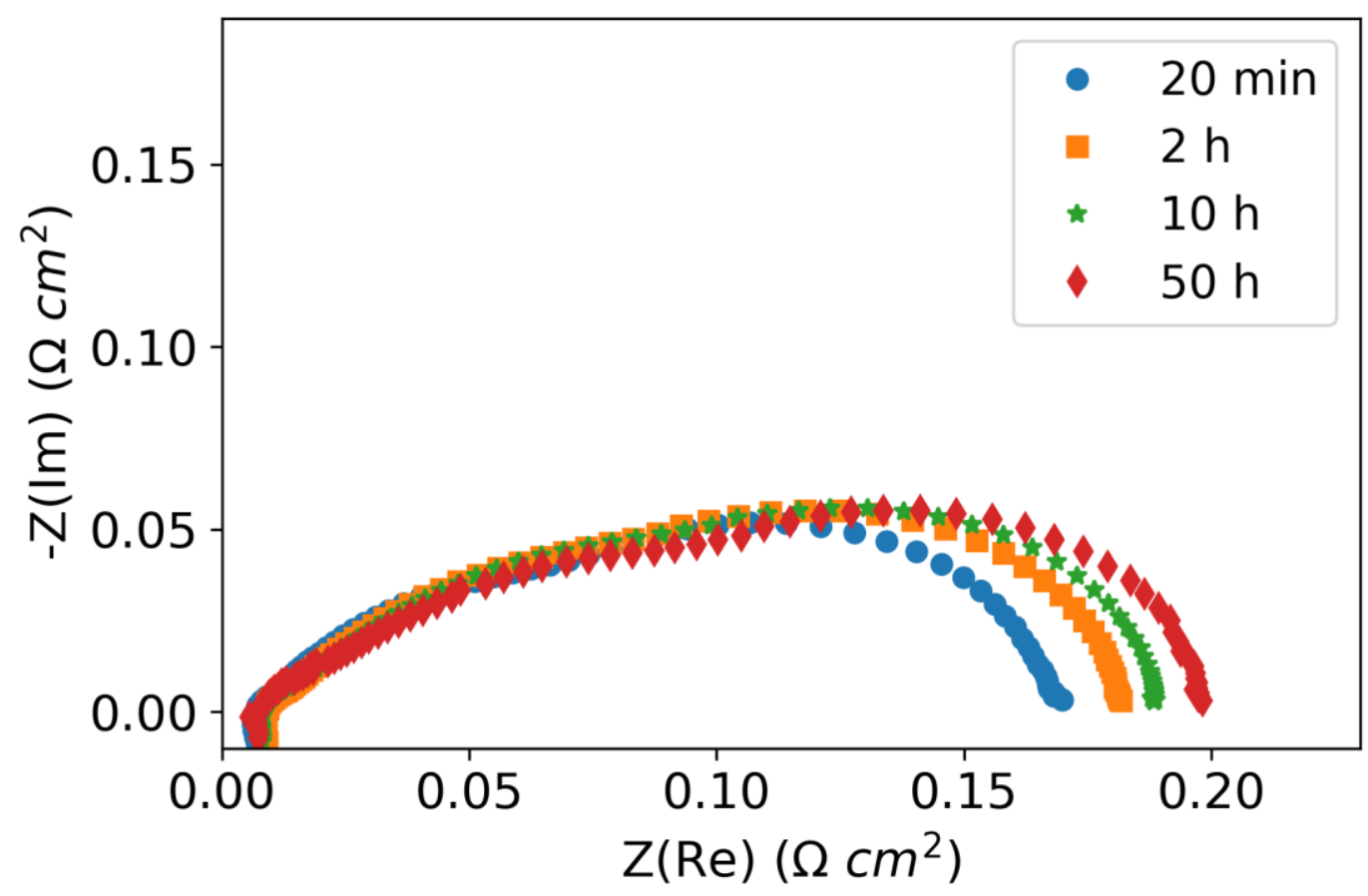

Figure 3 Nyquist plots of the symmetrical cells of Ni-CGO electrodes on YSZ electrolytes measured at $800{ }^{\circ} \mathrm{C}$ in $3 \% \mathrm{H}_{2} \mathrm{O}-5 \% \mathrm{H}_{2}-\mathrm{N}_{2}$. The spectra shown here are after $20 \mathrm{~min}, 2 \mathrm{~h}, 10 \mathrm{~h}$ and $50 \mathrm{~h}$ annealing respectively.

To investigate the microstructural evolution under high temperature annealing for the nanostructure electrode, the microstructure of an electrode after $70 \mathrm{~h}$ of aging is reconstructed by FIB-SEM tomography. The 3-D reconstruction in Figure 4 reveals the networks of $\mathrm{Ni}$ and $\mathrm{CGO}$ in the porous composite electrode, where the length scales of the tubular networks are observed to be in $100 \mathrm{~nm}$. The nanoscale features for both $\mathrm{Ni}$ and CGO are preserved to a large extent after high temperature annealing. The full volume of the 3-D tomography is $788 \mu \mathrm{m}^{3}$, in which the percolated TPB density is determined as $3 \mu \mathrm{m}^{-2}$ and the percolated DPB density (the interface between the CGO and the pore) as $2 \mu \mathrm{m}^{-1}$. Qualitatively, it is also observed in the 3-D reconstructed volume as shown in Figure 3 that the Ni and CGO networks are closely entangled with each other. Some extent of sintering happened in $\mathrm{Ni}$ because the pore space around the $\mathrm{Ni}$ particles in the cavities seen in Figure 2 is no longer found in the 3-D tomography in Figure 4. It is likely that under high temperature annealing, the Ni sinters to fill the pore space in the cavities which is indicated by the Ni phase in Figure 4. However, further growth of $\mathrm{Ni}$ in the composite structure extending beyond the cavities becomes more difficult due the presence of the neighbouring CGO phase. This may cause the stability observed in the longer time scale, as suggested by the slowdown of the increase in polarisation resistance shown in Figure 3. 

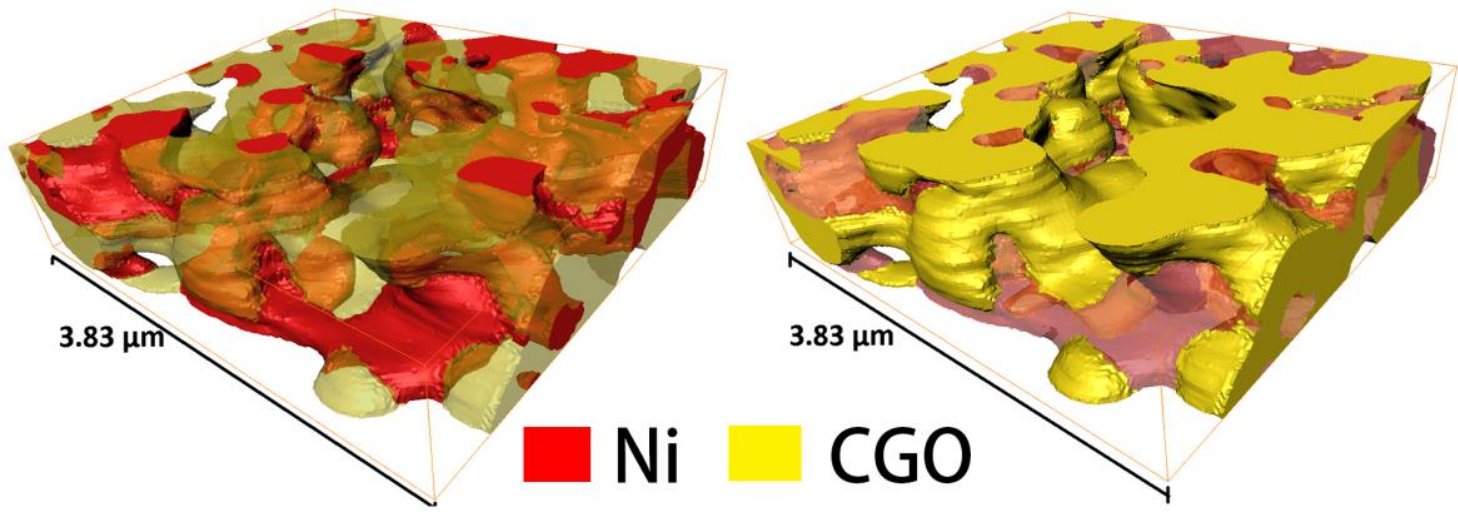

Figure 4 A section of the FIB-SEM 3-D tomography of the electrode aged at $800{ }^{\circ} \mathrm{C}$ in $3 \% \mathrm{H}_{2} \mathrm{O}-5 \% \mathrm{H}_{2}-\mathrm{N}_{2}$ for $70 \mathrm{~h}$. The 3-D reconstruction shown on the left highlights the $\mathrm{Ni}$ phase in red while the CGO phase in yellow is shown as translucent. Similarly, the reconstruction on the right highlight the CGO phase in yellow.

\section{Conclusion and Future Work}

Nano-structured Ni-CGO electrodes are fabricated via hydrothermal synthesis and cosintering. Composite nanopowder was used, which has $\mathrm{NiO}$ and $\mathrm{CGO}$ particles of $10 \mathrm{~nm}$ and a high BET surface area of $159 \mathrm{~m}^{2} \mathrm{~g}^{-1}$. The final Ni-CGO electrodes show features of $10-100 \mathrm{~nm}$ and porous structure. The total polarisation resistance of the electrode is initially $0.17 \Omega \mathrm{cm}^{2}$ and stabilises at $0.20 \Omega \mathrm{cm}^{2}$ after $50 \mathrm{~h}$ of aging at $800{ }^{\circ} \mathrm{C}$. FIB-SEM 3 -D tomography reveals that the $\mathrm{Ni}$ and CGO networks are closely entangled and the active TPB and DPB densities are $3 \mu \mathrm{m}^{-2}$ and $2 \mu \mathrm{m}^{-1}$ respectively after $70 \mathrm{~h}$ of annealing. The network features are still in $100 \mathrm{~nm}$ scale after annealing at $800{ }^{\circ} \mathrm{C}$. Future work will involve the 3-D tomography for electrodes before and after annealing to study the microstructural evolution for nanostructured porous electrodes.

\section{Acknowledgments}

The project received funding from EPSRC through EP/M014045/1 "Electrodes by Design - Microstructural Engineering of High-Performance Electrodes for Solid Oxide Fuel Cells". Jingyi Chen would like to acknowledge funding from Chinese Scholarship Council-Imperial Scholarship and a studentship from the EPSRC CDT for the Advanced Characterisation of Materials (EP/L015277/1).

\section{References}

1. M. J. Lee, J. H. Shin, M. J. Ji, and H. J. Hwang, J. Power Sources, 374, 181 (2018).

2. K.-Y. Lai and A. Manthiram, Chem. Mater., 30, 2515 (2018).

3. V. M. Janardhanan, V. Heuveline, and O. Deutschmann, J. Power Sources, 178, 368 (2008).

4. Y. Lu, P. Gasper, U. B. Pal, S. Gopalan, and S. N. Basu, J. Power Sources, 396, 257 (2018). 
5. A.M. Abdalla, S. Hossain, A.T. Azad, P.M.I. Petra, F. Begum, S.G. Eriksson, A.K. Azad, Renew. Sustain. Energy Rev., 82, 353 (2018).

6. Y. Ren, Y. Cheng, R. J. Gorte, and K. Huang, J. Electrochem. Soc., 164, F3001 (2017).

7. F. Si, L. Shao, X. Kang, C. Qin, K. Huang, X. Fu and J. Luo, Int. J. Hydrogen Energy, 5 (2018).

8. J. Chen, A. Bertei, E. Ruiz-Trejo, A. Atkinson, and N. P. Brandon, J. Electrochem. Soc., 164, F935 (2017).

9. X. Weng, D. Brett, V. Yufit, P. Shearing, N. Brandon, M. Reece, H. Yan, C. Tighe and J. A. Darr, Solid State Ionics, 181, 827 (2010).

10. L. Almar, B. Colldeforns, L. Yedra, S. Estradé, F. Peiró, A. Morata, T. Andreu and A. Tarancón, J. Mater. Chem. A, 1, 4531 (2013). 